\title{
BMJ Open Frequency-risk relationships between second-hand smoke exposure and respiratory symptoms among adolescents: a cross-sectional study in South China
}

\author{
Zhiyao Chen, ${ }^{1}$ Guocong Liu, ${ }^{2}$ Jianying Chen, ${ }^{3}$ Shunming Li, ${ }^{1}$ Ting Jiang, ${ }^{2}$ Bin $\mathrm{Xu},{ }^{2}$ \\ Xiaohua $\mathrm{Ye}^{1}$
}

To cite: Chen Z, Liu G,

Chen J, et al. Frequency-risk relationships between secondhand smoke exposure and respiratory symptoms among adolescents: a cross-sectional study in South China. BMJ Open 2018;8:e019875. doi:10.1136/ bmjopen-2017-019875

- Prepublication history for this paper is available online. To view these files, please visit the journal online (http://dx.doi. org/10.1136/bmjopen-2017019875).

ZC, GL and JC contributed equally.

Received 4 0ctober 2017 Revised 19 January 2018 Accepted 21 February 2018

Check for updates

${ }^{1}$ School of Public Health, Guangdong Pharmaceutical University, Guangzhou, China ${ }^{2}$ Health Education Section, Guangzhou Yuexiu Center for Disease Control and Prevention, Guangzhou, China

${ }^{3}$ General Department, Guangzhou Yuexiu Baiyun Community Health Service Center, Guangzhou, China

Correspondence to

Dr Xiaohua Ye;

smalltomato@163.com

\section{ABSTRACT}

Objectives Although previous studies have suggested an association between second-hand smoke (SHS) exposure and respiratory symptoms, current evidence is inconsistent. Additionally, it remains unclear whether there are frequency-risk relationships between SHS exposure and respiratory symptoms among adolescents.

Methods A cross-sectional survey was conducted using a stratified cluster sampling method to obtain a representative sample of high school students in Guangzhou, China. The respiratory symptoms were defined as persistent cough or sputum for three consecutive months during the past 12 months. Self-reported SHS exposure was defined as non-smokers' inhalation of the smoke exhaled from smokers on $\geq 1$ day a week in the past 7 days. The univariable and multivariable logistic regression models were fitted to explore the potential frequency-risk relationships between SHS exposure and respiratory symptoms.

Results Among 3575 students, the overall prevalence of SHS exposure was $69.2 \%$, including $49.5 \%$ for SHS in public places, $34.5 \%$ in homes, $22.7 \%$ in indoor campuses and $29.2 \%$ in outdoor campuses. There were significantly increased risks of having respiratory symptoms corresponding to SHS exposure in public places $(\mathrm{OR}=1.60$, $95 \% \mathrm{Cl} 1.30$ to 1.95$)$, in homes $(0 \mathrm{R}=1.53,95 \% \mathrm{Cl} 1.25$ to $1.87)$, in indoor campuses $(\mathrm{OR}=1.43,95 \% \mathrm{Cl} 1.14$ to 1.79$)$ and in outdoor campuses $(\mathrm{OR}=1.37,95 \% \mathrm{Cl} 1.10$ to 1.69$)$ using no exposure as reference. Notably, we observed monotonic frequency-risk relationships between settingspecific(eg, homes, public places and campuses) SHS exposure and respiratory symptoms.

Conclusion Our findings suggest that setting-specific SHS exposure is associated with a significant, dosedependent increase in risk of respiratory symptoms.

\section{INTRODUCTION}

It is well established that inhaling secondhand smoke (SHS) is harmful and that no scientific evidence establishes a risk-free level of exposure. ${ }^{12}$ Notably, a retrospective analysis of data from 192 countries revealed that $40 \%$
Strengths and limitations of this study

- This study aims to explore the potential frequencyrisk relationship between second-hand smoke (SHS) exposure and respiratory symptoms, and adds to the literature by focusing on Chinese tobacco control and Chinese youth along with its global context.

- This study differentiates SHS exposure in specific settings and specific sources to make exposure and potential associations clearer.

- SHS exposure and respiratory symptoms were self-reported, which is a limitation.

- Cross-sectional studies do not establish causal relationships but only depict associations. Our findings highlight the need for further longitudinal studies to establish the causal relationship and the biological mechanisms for the impact of SHS.

of children (including $35 \%$ of non-smoking women and $33 \%$ of non-smoking men) were exposed to SHS, and this exposure is estimated to result in an annual estimate of 603000 deaths attributable to SHS. ${ }^{3}$ Global youth tobacco surveillance also reported that nearly half the adolescents worldwide were exposed to SHS at home $(42.5 \%)$ and in public places $(55.1 \%)$, which constitutes a substantial public health threat and demands urgent intervention. ${ }^{4}$ China is the world's largest producer and consumer of tobacco. The 2010 Global Adult Tobacco Survey revealed that $72.4 \%$ adults in China were exposed to SHS, and the 2014 Chinese adolescents Tobacco Survey also reported that $72.9 \%$ adolescents in China had SHS exposure, suggesting that the tremendous burden from tobacco-induced diseases makes tobacco prevention an essential health priority in China. ${ }^{5}$ In recent years, much attention has been focused on SHS exposure in public places and in homes, 
but there are limited reports on SHS exposure in indoor and outdoor campuses among adolescents.

Epidemiological studies of adolescents have explored the associations between SHS exposure and respiratory symptoms (such as nose irritation, coughing and sore throat) or infection, ${ }^{7-11}$ but current evidence is inconsistent. Some studies demonstrated significantly positive associations, ${ }^{12} 13$ while the report from Malaysia revealed no association. ${ }^{14}$ Recent Chinese studies indicated that there were positive associations between household SHS exposure and respiratory symptoms in adolescents, but the association for SHS exposure in public places or in schools was unknown. ${ }^{15} 16$ SHS exposure occurs in varying amounts in public places, homes and other indoor spaces, but few studies have differentiated indoor and outdoor SHS exposure to make the setting-specific relationships between SHS exposure and respiratory symptoms clearer. Of particular concern is that little is known about the effects of campus SHS exposure on respiratory symptoms. Furthermore, it was unclear whether there are dose-response relationships between SHS exposure and respiratory symptoms. This study builds on previous literature to explore setting-specific (eg, public places, homes and campuses) and frequency-risk relationships between SHS exposure and respiratory symptoms among adolescents.

\section{METHODS}

The goals of the study were given to study participants and they were asked to express their willingness to participate. Before participating, written informed consent was obtained from their parents or guardians.

\section{Study design and data collection}

This cross-sectional study was conducted in Guangzhou, China, from March to April 2016. The target population was high school students. A stratified cluster sampling process was used to obtain a representative sample. Notably, middle schools in most part of China are generally rated by the Bureau of Education as key schools (or prestigious schools) and ordinary schools (or non-prestigious schools) according to level of education and the education quality. In the first stage, all high schools were divided into two categories (prestigious or non-prestigious schools). Three high schools were randomly sampled from prestigious schools, and four high schools were randomly sampled from non-prestigious schools, with the probability of selection proportional to the number of the schools. In the second stage, classes in the selected schools were randomly sampled proportionally to school enrolment size, and all students in sampled classes were eligible to participate.

All interviewers in each school were centrally trained to ensure that the survey was carried out according to the protocol and operation procedures were identical across all areas. After obtaining informed consent, eligible students were asked to complete a face-to-face survey by trained interviewers. A total of 3833 participants were enrolled in this study, and the effective response rate was $95.4 \%$ $(3657 / 3833)$. Only non-smokers were included in the analyses and a total of 3575 non-smokers were included in this study.

\section{Study variables}

The main outcome variable was self-reported respiratory symptoms. The respiratory symptoms were defined as persistent cough or sputum for 3 consecutive months during the past 12 months. ${ }^{17-19}$ The main independent variable of respiratory symptoms was self-reported SHS exposure, which was defined as non-smokers' inhalation of the smoke exhaled from smokers on $\geq 1$ day a week in the past 7 days for at least 6 months (first question: 'In the past 7 days, how many days did you breathe in SHS in homes (or indoor public places, indoor campuses, outdoor campuses)'; second question for those having SHS exposure: 'Did you breathe in SHS in this venue for at least 6 months?'). In order to recall SHS exposure for at least 6 months, we use both curriculum schedules and calendars as an assistive device to facilitate the recall time. Frequency of SHS exposure was continuous data (days/week), and was also categorised into three groups: $<1$ day/week (no exposure), ' $1-4$ days/week' and ' $5-7$ days/week'. Smoking status was classified as non-smokers and smokers (defined as 'has smoked over 100 cigarettes in their lifetime').

Covariates including potential mediators and confounders were chosen a priori on the basis of literature review. Potential covariates in our study included age (years), gender (male or female), grade (4-5 or $1-2$ ), only child (yes or no), monthly pocket money (<¥100, ¥100-399 or $\geq ¥ 400$ ), prestigious school (yes or no), father's education (primary school, middle school, or university and above), mother's education (primary school, middle school, or university and above) and asthma history (yes or no).

\section{Data analysis}

All data were entered in duplicate into EpiData V.3.1 database (The EpiData Association, Odense, Denmark). The univariable and multivariable logistic regression models were fitted to calculate the ORs and $95 \%$ CIs for evaluating the frequency-risk relationships between SHS exposure (including ordinal and continuous variables) and respiratory symptoms. Linear trends of SHS exposure were assessed by modelling exposure as continuous variables (arithmetic or logarithmic scale) or ordinal variables as multivariable models. A two-sided $p$ value of $<0.05$ was regarded as statistically significant. All statistical analyses were conducted using Stata V.14.0 (StataCorp, College Station, Texas, USA).

\section{RESULTS}

\section{Characteristics of the sample}

A total of 3575 non-smoking students were interviewed, of whom 477 (13.3\%) were classified as having respiratory symptoms. Participants' mean age was $15.0 \pm 1.8$ years, and 
$50.9 \%$ were male students. About $62.2 \%$ of the students were the only child in their family and $63.4 \%$ from prestigious schools. The overall prevalence of SHS exposure was $69.2 \%$, including $49.5 \%$ for SHS in indoor public places, $34.5 \%$ in homes, $22.7 \%$ in indoor campuses and $29.2 \%$ in outdoor campuses (table 1 ).

\section{Relationship between binary SHS exposure and respiratory symptoms}

The prevalence of respiratory symptoms was significantly higher in students with SHS exposure $(\mathrm{OR}=1.72$, $95 \%$ CI 1.35 to 2.17 , for SHS in general; OR $=1.60,95 \%$ CI 1.30 to 1.95 , for SHS in indoor public places; $\mathrm{OR}=1.53$, $95 \%$ CI 1.25 to 1.87 , for SHS in homes; OR $=1.43,95 \%$ CI 1.14 to 1.79 , for SHS in indoor campuses) than in those with no exposure (table 2). Similar positive associations were observed in students with SHS exposure in indoor campuses from smoking teachers $(\mathrm{OR}=1.34,95 \%$ CI 1.05 to 1.71$)$ or from smoking classmates $(\mathrm{OR}=1.54,95 \% \mathrm{CI}$ 1.15 to 2.06). Notably, the effects of SHS exposure in outdoor campuses cannot be ignored. Students with SHS exposure in outdoor campuses had significantly higher rates of respiratory symptoms $(\mathrm{OR}=1.37,95 \%$ CI 1.10 to 1.69) as compared with unexposed students, and there were similar positive associations between respiratory symptoms and SHS exposure in outdoor campuses from smoking teachers (OR=1.38, 95\% CI 1.09 to 1.75$)$ or from smoking classmates $(\mathrm{OR}=1.33,95 \%$ CI 1.03 to 1.71$)$.

\section{Relationship between ordinal SHS exposure and respiratory symptoms}

Compared with no SHS exposure, ordinal frequency of SHS exposure was associated with respiratory symptoms in an increasing manner (SHS in public places: $\mathrm{OR}=1$ for no exposure, $\mathrm{OR}=1.50$ for $1-4$ days/week, $\mathrm{OR}=1.87$ for 5-7 days/week, $p$ for linear trend $<0.001$; SHS in indoor campuses: $\mathrm{OR}=1$ for no exposure, $\mathrm{OR}=1.24$ for 1-4days/week, OR=1.84 for 5-7 days/week, $p$ for linear trend $<0.001$; table 3 ). When examining these associations by source of exposure, significant increasing trends were observed for SHS exposure in indoor campuses from smoking teachers ( $p$ for linear trend $=0.001$ ) and from smoking classmates ( $p$ for linear trend $=0.005$ ). Additionally, there was a significantly increasing relationship between ordinal frequency of SHS exposure in outdoor campuses and respiratory symptoms $(\mathrm{OR}=1$ for no exposure, $\mathrm{OR}=1.28$ for $1-4$ days/week, $\mathrm{OR}=1.56$ for $5-7$ days/week, $p$ for linear trend $=0.007$; table 3 ), and similar increasing trends were observed for SHS exposure in outdoor campuses from smoking teachers ( $p$ for linear trend $=0.004$ ) and from smoking classmates ( $p$ for linear trend $=0.006$ ). However, no increasing trend was observed for SHS exposure in homes.

\section{Relationship between continuous SHS exposure and respiratory symptoms}

As for continuous SHS exposure, there were significant frequency-risk relationships between indoor SHS
Table 1 Demographic characteristics of the study participants

\begin{tabular}{|c|c|c|}
\hline Characteristics & $\mathbf{n}$ & $\%$ \\
\hline \multicolumn{3}{|c|}{ Respiratory symptoms } \\
\hline No & 3098 & 86.7 \\
\hline Yes & 477 & 13.3 \\
\hline \multicolumn{3}{|c|}{ SHS exposure in general } \\
\hline No & 1101 & 30.8 \\
\hline Yes & 2474 & 69.2 \\
\hline \multicolumn{3}{|c|}{$\begin{array}{l}\text { SHS exposure in indoor public } \\
\text { places }\end{array}$} \\
\hline No & 1806 & 50.5 \\
\hline Yes & 1769 & 49.5 \\
\hline \multicolumn{3}{|c|}{ SHS exposure in homes } \\
\hline No & 2342 & 65.5 \\
\hline Yes & 1233 & 34.5 \\
\hline \multicolumn{3}{|c|}{ SHS exposure in indoor campuses } \\
\hline No & 2763 & 77.3 \\
\hline Yes & 812 & 22.7 \\
\hline
\end{tabular}

SHS exposure in outdoor campuses

\begin{tabular}{|c|c|c|}
\hline No & 2532 & 70.8 \\
\hline Yes & 1043 & 29.2 \\
\hline \multicolumn{3}{|l|}{ Asthma history } \\
\hline No & 3514 & 98.3 \\
\hline Yes & 61 & 1.7 \\
\hline \multicolumn{3}{|l|}{ Grade } \\
\hline $1-2$ & 2329 & 65.2 \\
\hline $4-5$ & 1246 & 34.8 \\
\hline \multicolumn{3}{|l|}{ Only child } \\
\hline No & 1353 & 37.8 \\
\hline Yes & 2222 & 62.2 \\
\hline \multicolumn{3}{|l|}{ Gender } \\
\hline Male & 1818 & 50.9 \\
\hline Female & 1757 & 49.1 \\
\hline \multicolumn{3}{|l|}{ Pocket money monthly( $¥)$} \\
\hline$<100$ & 2039 & 57.0 \\
\hline $100-399$ & 1125 & 31.5 \\
\hline$\geq 400$ & 411 & 11.5 \\
\hline \multicolumn{3}{|l|}{ Father's education } \\
\hline Primary school & 838 & 23.4 \\
\hline Middle school & 1215 & 34.0 \\
\hline University and above & 1522 & 42.6 \\
\hline \multicolumn{3}{|l|}{ Mother's education } \\
\hline Primary school & 978 & 27.4 \\
\hline Middle school & 1165 & 32.6 \\
\hline University and above & 1432 & 40.0 \\
\hline
\end{tabular}

$\%$, the proportion of participants.; $n$, number of participants. SHS, second-hand smoke. 
Table 2 Relationship between binary SHS exposure and respiratory symptoms

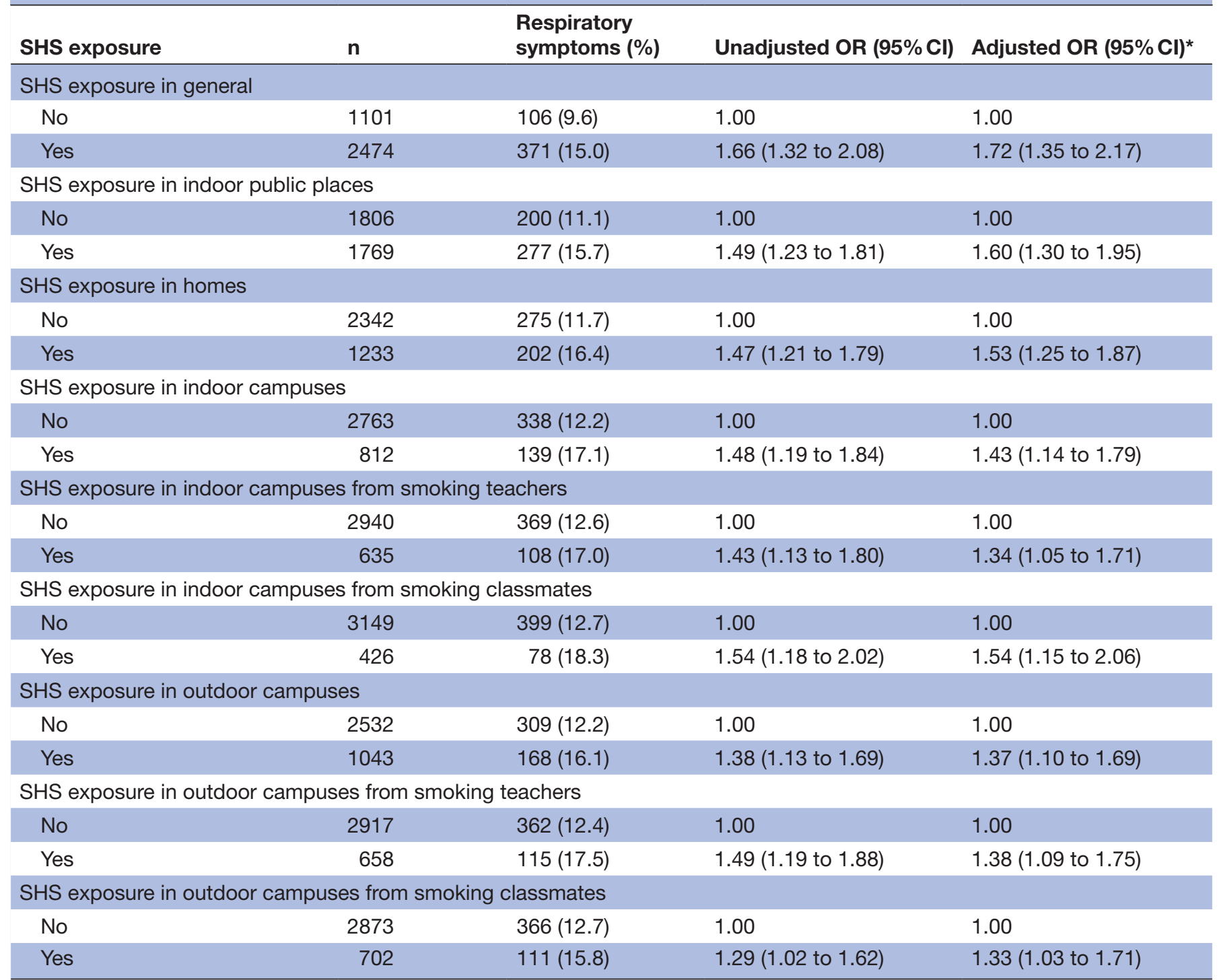

*adjusted for gender (male vs female), grade (4-5 vs 1-2), only child (yes vs no) and asthma history (yes vs no).

$\mathrm{n}$, number of participants; SHS, second-hand smoke.

exposure and respiratory symptoms $(\mathrm{OR}=2.30,95 \% \mathrm{CI}$ 1.67 to 3.16, for SHS in indoor public places; OR $=1.64$, $95 \%$ CI 1.23 to 2.20, for SHS in homes; OR=2.09, 95\% CI 1.42 to 3.07 , for SHS in indoor campuses; $\mathrm{OR}=1.70$, $95 \%$ CI 1.18 to 2.47 , for SHS in outdoor campuses; table 3). When examining these associations by source of exposure, there were similar frequency-risk relationships for SHS exposure in indoor or outdoor campuses (table 3). Additionally, we observed a monotonically increasing frequency-risk trend for SHS exposure in indoor public places (figure 1A), in homes (figure 1B), in indoor campuses (figure 2A) or in outdoor campuses (figure 2B). When examining these trends by source of exposure, there were similar increasing frequencyrisk trends for SHS exposure from smoking teachers (figure 3A for indoor SHS and figure 3B for outdoor SHS) and from smoking classmates (figure 4A for indoor SHS and figure 4B for outdoor SHS).

\section{DISCUSSION}

This observational study showed that non-smoking students with setting-specific SHS exposure experienced significantly higher risks of respiratory symptoms than those with no exposure. The most striking findings from this study were that there were monotonically increasing frequency-risk relationships between setting-specific SHS exposure and respiratory symptoms. When examining these associations by source of exposure, there were similar monotonically increasing frequency-risk relationships for SHS exposure from smoking teachers and from smoking classmates.

It is well known that there is no risk-free level of exposure to SHS. Although previous studies have focused on SHS exposure among Chinese adolescents, ${ }^{15} 1620$ there are limited reports regarding SHS exposure in specific settings and specific sources. According to the partial smoke-free legislation implemented in Guangzhou on 
Table 3 Relationship between frequency of SHS exposure and respiratory symptoms

\begin{tabular}{|c|c|c|c|c|}
\hline Frequency of SHS exposure & $\mathbf{n}$ & $\begin{array}{l}\text { Respiratory } \\
\text { symptoms (\%) }\end{array}$ & Unadjusted OR $(95 \% \mathrm{Cl})$ & Adjusted OR $(95 \% \mathrm{Cl})^{*}$ \\
\hline \multicolumn{5}{|c|}{ SHS exposure in indoor public places } \\
\hline No exposure & 1806 & $200(11.1)$ & 1.00 & 1.00 \\
\hline 1 to 4 days/week & 1242 & $184(14.8)$ & $1.40(1.13$ to 1.73$)$ & $1.50(1.20$ to 1.86$)$ \\
\hline 5 to 7 days/week & 527 & $93(17.7)$ & $1.72(1.32$ to 2.25$)$ & 1.87 (1.41 to 2.46$)$ \\
\hline \multicolumn{3}{|c|}{ Continuous SHS in indoor public places $†$} & 2.06 (1.52 to 2.80$)$ & 2.30 (1.67 to 3.16$)$ \\
\hline \multicolumn{5}{|l|}{ SHS exposure in homes } \\
\hline No exposure & 2342 & $275(11.7)$ & 1.00 & 1.00 \\
\hline 1 to 4 days/week & 570 & $97(17.0)$ & 1.54 (1.20 to 1.98$)$ & 1.62 (1.25 to 2.09$)$ \\
\hline 5 to 7 days/week & 663 & $105(15.8)$ & 1.41 (1.11 to 1.80$)$ & 1.45 (1.13 to 1.87$)$ \\
\hline Continuous SHS in homes $†$ & & & 1.56 (1.18 to 2.07$)$ & 1.64 (1.23 to 2.20$)$ \\
\hline \multicolumn{5}{|c|}{ SHS exposure in indoor campuses } \\
\hline No exposure & 2763 & $338(12.2)$ & 1.00 & 1.00 \\
\hline 1 to 4 days/week & 539 & $81(15.0)$ & 1.27 (0.98 to 1.65$)$ & 1.24 (0.95 to 1.63$)$ \\
\hline 5 to 7 days/week & 273 & $58(21.3)$ & 1.94 (1.42 to 2.64$)$ & 1.84 (1.32 to 2.56$)$ \\
\hline \multicolumn{3}{|c|}{ Continuous SHS in indoor campuses $†$} & 2.19 (1.53 to 3.12$)$ & 2.09 (1.42 to 3.07$)$ \\
\hline \multicolumn{5}{|c|}{ SHS exposure in indoor campuses from smoking teachers } \\
\hline No exposure & 2940 & $369(12.6)$ & 1.00 & 1.00 \\
\hline 1 to 4 days/week & 412 & $59(14.3)$ & 1.16 (0.87 to 1.57$)$ & 1.13 (0.84 to 1.53$)$ \\
\hline 5 to 7 days/week & 223 & $49(22.0)$ & $1.96(1.40$ to 2.74$)$ & $1.78(1.25$ to 2.53$)$ \\
\hline \multicolumn{3}{|c|}{ Continuous SHS in indoor campuses from smoking teachers $\dagger$} & 2.27 (1.54 to 3.33$)$ & 2.06 (1.37 to 3.09$)$ \\
\hline \multicolumn{5}{|c|}{ SHS exposure in indoor campuses from smoking classmates } \\
\hline No exposure & 3149 & $399(12.7)$ & 1.00 & 1.00 \\
\hline 1 to 4 days/week & 271 & $45(16.6)$ & 1.37 (0.98 to 1.92$)$ & 1.38 (0.97 to 1.97$)$ \\
\hline 5 to 7 days/week & 155 & $33(21.3)$ & $1.86(1.25$ to 2.78$)$ & 1.84 (1.20 to 2.82$)$ \\
\hline \multicolumn{3}{|c|}{ Continuous SHS in indoor campuses from smoking classmates $†$} & 2.04 (1.30 to 3.20$)$ & 2.00 (1.22 to 3.26$)$ \\
\hline \multicolumn{5}{|c|}{ SHS exposure in outdoor campuses } \\
\hline No exposure & 2532 & $309(12.2)$ & 1.00 & 1.00 \\
\hline 1 to 4 days/week & 704 & $105(14.9)$ & 1.26 (0.99 to 1.60$)$ & 1.28 (1.01 to 1.64$)$ \\
\hline 5 to 7 days/week & 339 & $63(18.6)$ & 1.64 (1.22 to 2.21$)$ & 1.56 (1.13 to 2.15$)$ \\
\hline \multicolumn{3}{|c|}{ Continuous SHS exposure in outdoor campuses $\dagger$} & 1.79 (1.27 to 2.51$)$ & 1.70 (1.18 to 2.47$)$ \\
\hline \multicolumn{5}{|c|}{ SHS exposure in outdoor campuses from smoking teachers } \\
\hline No exposure & 2917 & $362(12.4)$ & 1.00 & 1.00 \\
\hline 1 to 4 days/week & 456 & $71(15.6)$ & 1.30 (0.99 to 1.72$)$ & 1.24 (0.94 to 1.64$)$ \\
\hline 5 to 7 days/week & 202 & $44(21.8)$ & 1.97 (1.38 to 2.79$)$ & $1.74(1.20$ to 2.50$)$ \\
\hline \multicolumn{3}{|c|}{ Continuous SHS in outdoor campuses from smoking teachers $\dagger$} & $2.53(1.71$ to 3.74$)$ & $2.20(1.45$ to 3.33$)$ \\
\hline \multicolumn{5}{|c|}{ SHS exposure in outdoor campuses from smoking classmates } \\
\hline No exposure & 2873 & $366(12.7)$ & 1.00 & 1.00 \\
\hline 1 to 4 days/week & 451 & $62(13.8)$ & 1.09 (0.82 to 1.46$)$ & 1.16 (0.86 to 1.57$)$ \\
\hline 5 to 7 days/week & 251 & $49(19.5)$ & 1.66 (1.19 to 2.31$)$ & 1.66 (1.16 to 2.39$)$ \\
\hline \multicolumn{3}{|c|}{ Continuous SHS in outdoor campuses from smoking classmates $\dagger$} & 1.55 (1.05 to 2.30$)$ & 1.58 (1.03 to 2.42$)$ \\
\hline
\end{tabular}

*Adjusted for gender (male vs female), grade (4-5 vs 1-2), only child (yes vs no) and asthma history (yes vs no). †Use logarithmic exposure (days/week) in the model.

n, number of participants; SHS, second-hand smoke. 

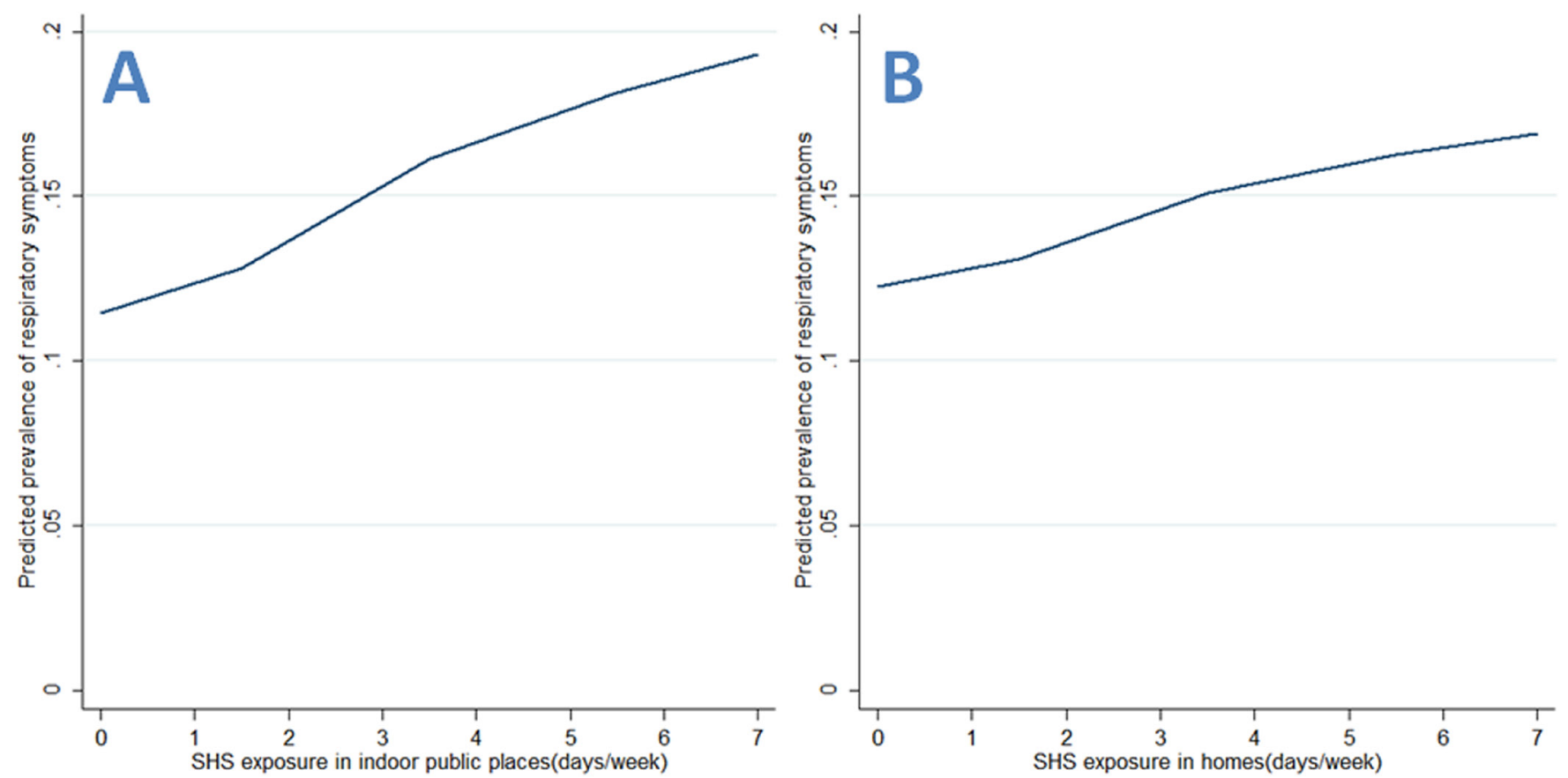

Figure 1 Predicted prevalence of respiratory symptoms based on second-hand smoke (SHS) exposure (A: exposure in indoor public places; B: exposure in homes).

1 September 2010, full smoke-free ban covered indoor campuses, outdoor campuses and most indoor public places, but did not cover homes. It is disappointing that SHS exposure in schools was not eliminated, and was still at a high level (22.7\% for SHS exposure in indoor campuses; $29.2 \%$ for SHS exposure in outdoor campuses). This observation may be due to poor compliance with the full smoke-free ban in campuses, since we observed that SHS exposure among students was mainly from smoking teachers and smoking classmates in both indoor and outdoor campuses. Similarly, a recent population-based study in Tehran showed that about $30 \%$ non-smoking students have been exposed to SHS from smoking teachers in indoor or outdoor campuses, ${ }^{21}$ and
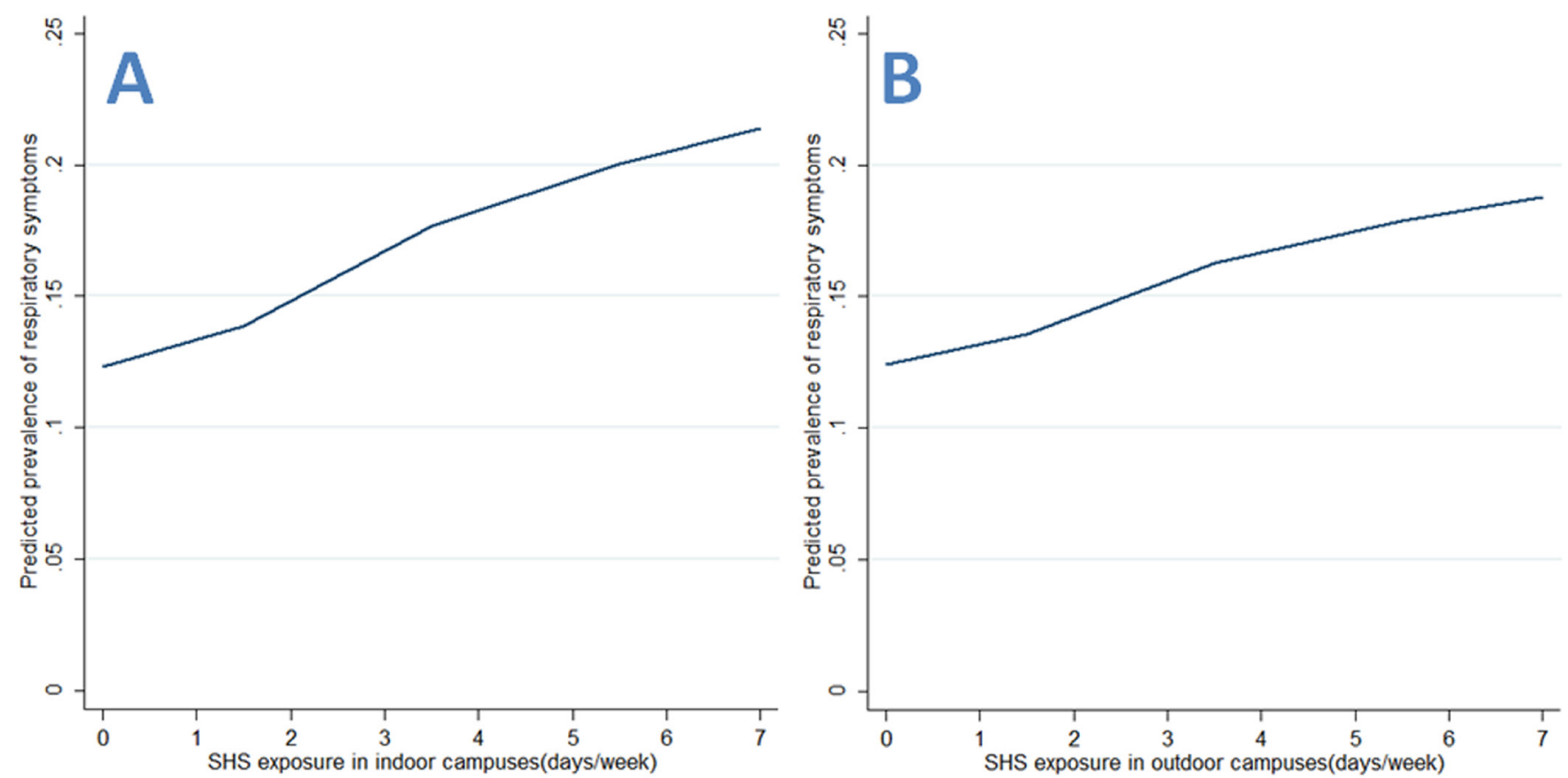

Figure 2 Predicted prevalence of respiratory symptoms based on second-hand smoke (SHS) exposure in campuses (A: exposure in indoor campuses; B: exposure in outdoor campuses). 

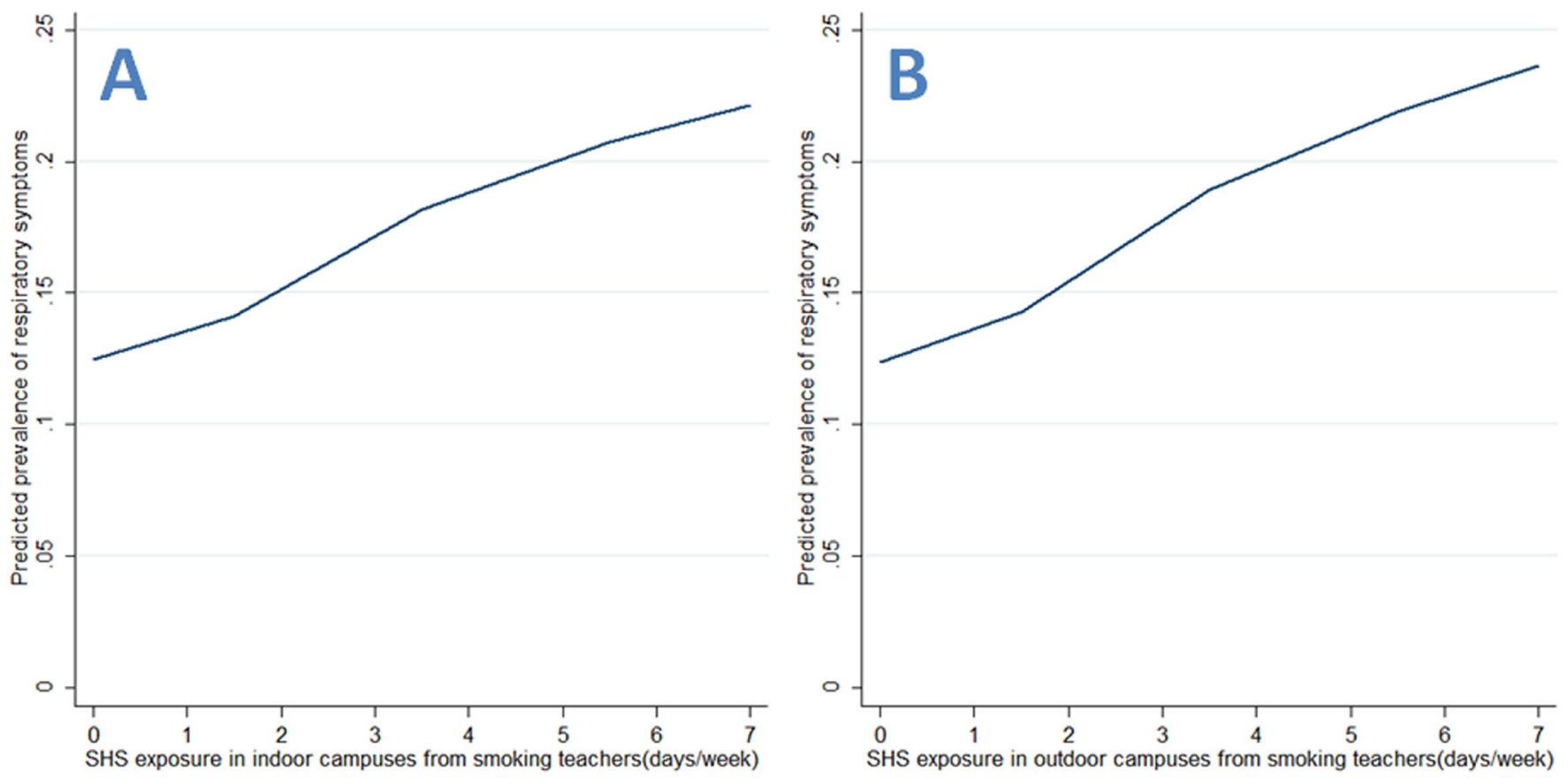

Figure 3 Predicted prevalence of respiratory symptoms based on second-hand smoke (SHS) exposure from smoking teachers (A: exposure in indoor campuses; B: exposure in outdoor campuses).

another survey of Chinese college students reported that $37 \%$ of non-smokers had SHS exposure from smoking teachers. ${ }^{20}$ More disappointing was that SHS exposure in indoor public places was remarkably high in $49.5 \%$ of non-smokers in this study, which is similar to results from the latest study on Guangzhou adults $(50.3 \%)$ and the Global Youth Tobacco Survey $(47.8 \%) .{ }^{22} 23$ After the implementation of a smoke-free legislation, very few respondents $(1 \%-2 \%)$ reported smoking in public places in England, ${ }^{24}$ but smoking behaviours still remained high in public places in Guangzhou because of unwillingness of the policy makers to implement tougher smoke-free policies and poor compliance with the smoke-free law among smokers. ${ }^{23}$ These findings reveal that a partial
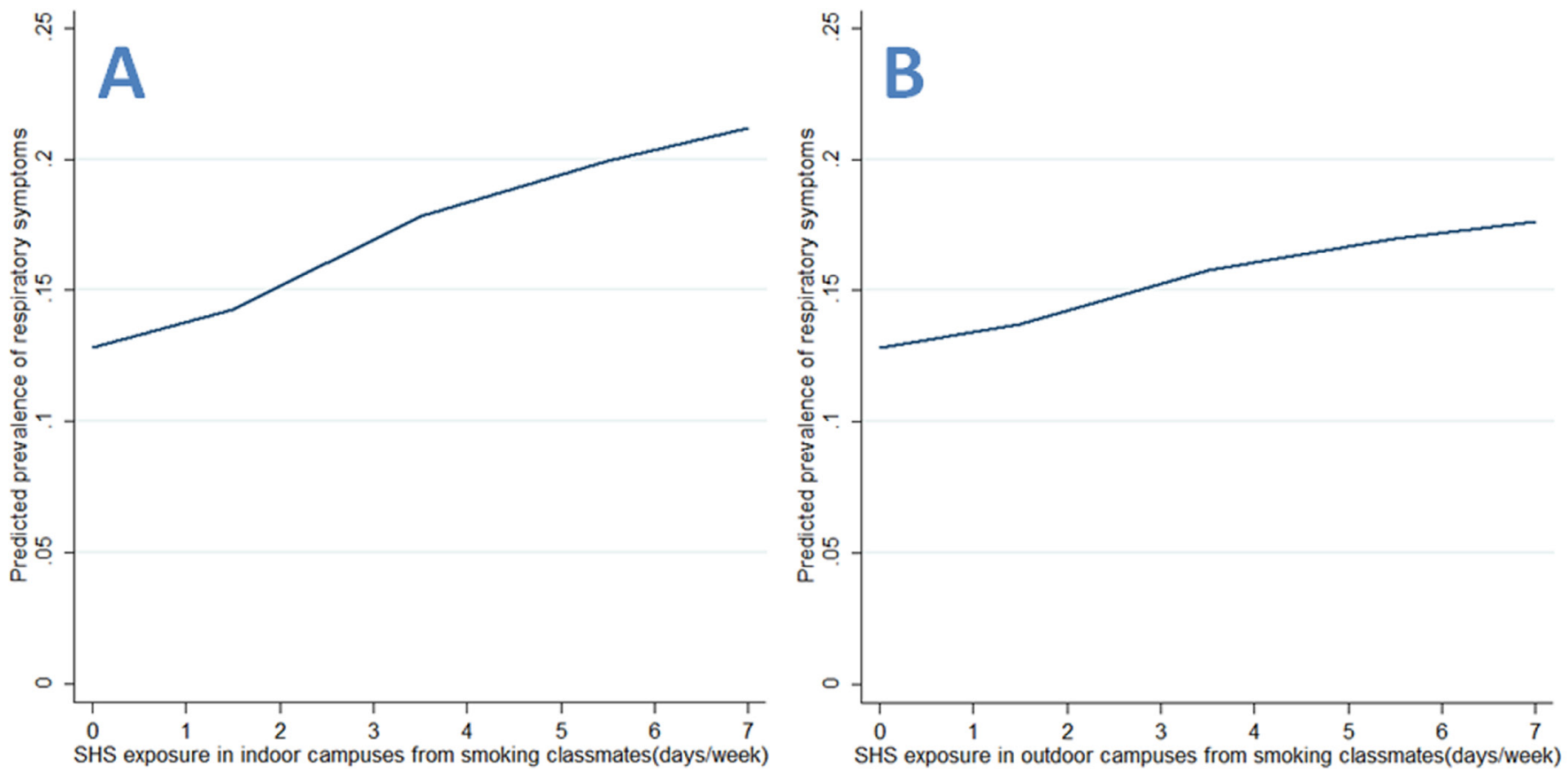

Figure 4 Predicted prevalence of respiratory symptoms based on second-hand smoke (SHS) exposure from smoking classmates (A: exposure in indoor campuses; B: exposure in outdoor campuses). 
smoke-free legislation has a weak impact on smoking cessation, but a comprehensive smoke-free legislation can substantially attenuate smoking behaviours, which point out the urgent need for a comprehensive smokefree legislation covering all public places in Guangzhou to protect the public from SHS hazards.

A few published studies have indicated that SHS exposure may be a risk factor for respiratory symptoms, but the potential relationship for setting-specific exposure was still unclear. ${ }^{15162526}$ Recent studies of Chinese adolescents indicated that there were positive associations between household SHS exposure and respiratory symptoms, but the association for SHS exposure in public places or in schools was unknown. ${ }^{15} 16$ In addition, the surveys of London casino workers and Shanghai workers revealed that there was a significant association between SHS exposure at work and respiratory symptoms, but the association for SHS exposure in homes or in public places was unknown. ${ }^{25}{ }^{26}$ It is noteworthy that the influence of SHS exposure from indoor campuses on respiratory symptoms is still unclear, and the potential dose-response relationship between frequency of SHS exposure and respiratory symptoms is also uncertain. We found that there were positive and frequency-risk relationships between setting-specific SHS exposure and respiratory symptoms. When examining the associations by source of exposure, there was still evidence of similar dose-response relationships for SHS exposure in indoor campuses from smoking teachers and smoking classmates. These findings provide new evidence of dose-response relationships between SHS exposure and respiratory symptoms among adolescents. Further research is needed to establish the causal relationship, and confirm that elimination of SHS exposure (or stricter smoke-free legislation in Guangzhou) will lead to a reduction in respiratory symptoms among adolescents. Although the 2010 report of the Surgeon General explained beyond a shadow of a doubt how tobacco smoke causes disease,${ }^{27}$ additional research should establish the potential biological mechanisms for the impact of SHS.

Globally, outdoor smoking restrictions are uncommon, though the outdoor-campus smoking bans were implemented in Guangzhou city on 1 September 2010. A few published studies have indicated that smoking increases particulate matter with an aerodynamic diameter $\leq 2.5 \mu \mathrm{m}\left(\mathrm{PM}_{2.5}\right)$ concentrations in outdoor areas to levels that are potentially hazardous to health, ${ }^{28}{ }^{29}$ but research linking SHS exposures from outdoor environments to health effects is still rare. Notably, the potential relationship between outdoor SHS exposure and respiratory symptoms is still unclear. To our knowledge, this is the first study to reveal the relationship between SHS exposure in outdoor campuses and respiratory symptoms among adolescents, and found that outdoor SHS exposure was positively associated with respiratory symptoms in a monotonically increasing trend. When examining the associations by source of exposure, there were still similar frequency-risk relationships for SHS exposure in outdoor campuses from smoking teachers and smoking classmates. Although outdoor SHS is more transient than indoor SHS, evidence from review of the research literature on SHS levels in outdoor hospitality venues suggested that tobacco-generated $\mathrm{PM}_{2.5}$ in outdoor settings may occasionally be equivalent to or higher than levels observed in indoor settings when smoking is permitted at close proximity. ${ }^{28}$ These findings provide more evidence for the adverse effects of outdoor SHS exposure on human respiratory symptoms, and also support growing concern about SHS exposure in outdoor campuses. Future studies on school SHS exposure in adolescents and protective measures against SHS should take outdoor campuses' SHS into consideration.

This study adds to the literature by focusing on Chinese tobacco control and Chinese youth along with its global context. Additionally, we contribute to the literature by exploring the potential frequencyrisk relationships and differentiating SHS exposure in specific settings and specific sources to make exposure and potential relationships clearer. There are also some potential limitations in this study. First, all data were self-reported, including SHS exposure and respiratory symptoms. For SHS exposure, biochemical measures can give objective measurements, but cannot distinguish the sources of exposure, the key factors in this study. A previous survey has found that school children are capable of reporting their health conditions reliably, ${ }^{30}$ and the presence of frequent cough and phlegm was quite obvious to avoid measurement error. Second, causal association between SHS exposure and respiratory symptoms could not be ascertained due to the cross-sectional design. However, the notion of reverse causation that students with respiratory symptoms deliberately increased their exposure to noxious SHS seems improbable. The strong associations observed in other studies also supported our data validity and provided support for the deduction of causation. ${ }^{15} 3132$ Finally, few people would be completely unexposed to SHS in densely populated Guangzhou even now, when smoking was still allowed in public places (eg, cafes, bars, night clubs, amusement parks, restaurants and workplaces). Therefore, the control groups who reported no SHS exposure have probably underestimated their exposure, and the risk for respiratory symptoms in these groups would also be underestimated.

In conclusion, SHS exposure in indoor and outdoor campuses is still at a high level, which suggests poor compliance with the full smoke-free ban in schools and supports growing concern about SHS exposure in campuses. Additionally, this study contributes to the literature by finding monotonically increasing frequency-risk relationships between SHS exposure and respiratory symptoms among adolescents in addition to differentiating SHS exposure in specific settings and specific sources to make these relationships clearer. Future longitudinal studies are needed 
to establish the causal relationship and the biological mechanisms for the impact of SHS.

Contributors ZC, GL, SL, TJ, BX, JC and XY were involved in the design of the study, data analysis and writing of the draft of the manuscript. All the authors read and approved the final version of the manuscript.

Funding This research received no specific grant from any funding agency in the public, commercial or not-for-profit sectors.

Competing interests None declared.

Patient consent Parental/guardian consent obtained.

Ethics approval The Ethics Committee of Guangdong Pharmaceutical University.

Provenance and peer review Not commissioned; externally peer reviewed.

Data sharing statement № additional data are available.

Open Access This is an Open Access article distributed in accordance with the Creative Commons Attribution Non Commercial (CC BY-NC 4.0) license, which permits others to distribute, remix, adapt, build upon this work non-commercially, and license their derivative works on different terms, provided the original work is properly cited and the use is non-commercial. See: http://creativecommons.org/ licenses/by-nc/4.0/

(c) Article author(s) (or their employer(s) unless otherwise stated in the text of the article) 2018. All rights reserved. No commercial use is permitted unless otherwise expressly granted.

\section{REFERENCES}

1. Makadia LD, Roper PJ, Andrews JO, et al. Tobacco use and smoke exposure in children: new trends, harm, and strategies to improve health outcomes. Curr Allergy Asthma Rep 2017;17:55.

2. Office on Smoking and Health (US). The health consequences of involuntary exposure to tobacco smoke: a report of the surgeon general. Atlanta (GA): Centers for Disease Control and Prevention (US), 2006.

3. Oberg M, Jaakkola MS, Woodward A, et al. Worldwide burden of disease from exposure to second-hand smoke: a retrospective analysis of data from 192 countries. Lancet 2011;377:139-46.

4. Warren CW, Jones NR, Peruga A, et al. Global youth tobacco surveillance, 2000-2007. MMWR Surveill Sum 2008;57:1-28.

5. Chinese Center for Disease Control and Prevention. Global adult tobacco survey (gats) China 2010 country report. 2010 http://ww w.notc.org.cn/newjcpg/201304/W020121108628365808856.pdf.

6. Chinese Center for Disease Control and Prevention. Report on tobacco use in Chinese adolescents: 2014. China: Beijing, Tobacco Control Office, 2014

7. Hisam A, Rahman MU, Kadir E, et al. Proportion of exposure of passive smoking in teenage group and symptoms precipitated after exposure to second hand smoke. J Coll Physicians Surg Pak 2014;24:446-8.

8. Schick SF, van den Vossenberg G, Luo A, et al. Thirty minuteexposure to aged cigarette smoke increases nasal congestion in nonsmokers. J Toxicol Environ Health A 2013;76:601-13.

9. Kabir Z, Manning PJ, Holohan J, et al. Second-hand smoke exposure in cars and respiratory health effects in children. Eur Respir $J$ 2009;34:629-33.

10. Clark BR, Burkett SA, Andridge RR, et al. Evidence of high rates of undiagnosed asthma in central Ohio elementary schoolchildren. $J$ Sch Health 2013;83:896-906.

11. Jones LL, Hashim A, McKeever T, et al. Parental and household smoking and the increased risk of bronchitis, bronchiolitis and other lower respiratory infections in infancy: systematic review and metaanalysis. Respir Res 2011;12:5.

12. Jang AS, Choi IS, Lee $S$, et al. The effect of passive smoking on asthma symptoms, atopy,and airway hyperresponsiveness in schoolchildren. J Korean Med Sci 2004;19:214-7.

13. Bakoula CG, Kafritsa YJ, Kavadias GD, et al. Objective passivesmoking indicators and respiratory morbidity in young children. Lancet 1995;346:280-1.

14. Zulkifli A, Abidin NZ, Abidin EZ, et al. Burden of household smoking habits on the occurrence of respiratory symptoms among Malaysian adolescents. Iranian Journal of Public Health 2014;43:42-52.

15. Leung LT, Ho SY, Wang MP, et al. Exposure to secondhand smoke from neighbours and respiratory symptoms in never-smoking adolescents in Hong Kong: a cross-sectional study. BMJ Open 2015;5:e008607.

16. He QQ, Wong TW, Du L, et al. Environmental tobacco smoke exposure and Chinese schoolchildren's respiratory health: a prospective cohort study. Am J Prev Med 2011;41:487-93.

17. Peters J, Hedley AJ, Wong CM, et al. Effects of an ambient air pollution intervention and environmental tobacco smoke on children's respiratory health in Hong Kong. Int $J$ Epidemiol 1996;25:821-8.

18. Cotes JE, Chinn DJ. MRC questionnaire (MRCQ) on respiratory symptoms. Occup Med 2007;57:388.

19. Ho SY, Wang MP, Lo WS, Sy H, Ws L, et al. Comprehensive smokefree legislation and displacement of smoking into the homes of young children in Hong Kong. Tob Control 2010;19:129-33.

20. Gong M, Liang ZY, Zhang YY, et al. Implementation of the tobaccofree campus policy on college campuses: evidence from a survey of college students in Beijing. Nicotine Tob Res 2016;18:2083-91.

21. Emami H, Naserikouzehgarani G, Saeedfar K, et al. The correlation of student's smoking and their perceived exposure to their teacher's smoking in tehran: a population based study. Journal of Shahid Sadoughi University of Medical Sciences 2010;18:98-110.

22. Centers for Disease Control and Prevention (CDC). Exposure to secondhand smoke among students aged 13-15 years--worldwide, 2000-2007. MMWR Morb Mortal Wkly Rep 2007;56:497-500.

23. Ye X, Yao Z, Gao Y, et al. Second-hand smoke exposure in different types of venues: before and after the implementation of smoke-free legislation in Guangzhou, China. BMJ Open 2014;4:e004273.

24. Lee JT, Glantz SA, Millett C. Effect of smoke-free legislation on adult smoking behaviour in England in the 18 months following implementation. PLoS One 2011;6:e20933.

25. Pilkington PA, Gray S, Gilmore AB. Health impacts of exposure to second hand smoke (SHS) amongst a highly exposed workforce: survey of London casino workers. BMC Public Health 2007;7:257.

26. Zheng P, Li W, Chapman S, et al. Workplace exposure to secondhand smoke and its association with respiratory symptoms-a cross-sectional study among workers in Shanghai. Tob Control 2011;20:58-63.

27. Centers for Disease Control and Prevention (US). How tobacco smoke causes disease: the biology and behavioral basis for smokingattributable disease. Atlanta (GA): Centers for Disease Control and Prevention (US), 2010.

28. Licht AS, Hyland A, Travers MJ, et al. Secondhand smoke exposure levels in outdoor hospitality venues: a qualitative and quantitative review of the research literature. Tob Control 2013;22:172-9.

29. Stafford J, Daube M, Franklin P. Second hand smoke in alfresco areas. Health Promot J Austr 2010;21:99-105.

30. Riley AW. Evidence that school-age children can self-report on their health. Ambul Pediatr 2004:4:371-6.

31. Lai HK, Ho SY, Wang MP, et al. Secondhand smoke and respiratory symptoms among adolescent current smokers. Pediatrics 2009;124:1306-10.

32. Lam TH, Chung SF, Betson CL, et al. Respiratory symptoms due to active and passive smoking in junior secondary school students in Hong Kong. Int J Epidemiol 1998;27:41-8. 